Proceedings of the 2011 Winter Simulation Conference

S. Jain, R.R. Creasey, J. Himmelspach, K.P. White, and M. Fu, eds.

\title{
IMPLEMENTING VIRTUAL METROLOGY INTO SEMICONDUCTOR PRODUCTION PROCESSES - AN INVESTMENT ASSESSMENT
}

\author{
Matthias Koitzsch \\ Fraunhofer IISB \\ Schottkystr. 10 \\ 91058 Erlangen, GERMANY \\ Humbert Noll \\ Alexander Nemecek \\ University of Applied Sciences \\ Johannes Guttenberg-Str. 3 \\ 2700 Wiener Neustadt, AUSTRIA
}

\author{
Jochen Merhof \\ Markus Michl \\ FAPS University of Erlangen-Nuremberg \\ Egerlandstr. 7-9 \\ 91058 Erlangen, GERMANY
}

\author{
Alfred Honold \\ Gerhard Kleineidam \\ InReCon AG \\ Von-Henle-Ring 44 \\ 93161 Sinzing, GERMANY
}

\author{
Holger Lebrecht \\ Infineon Technologies AG \\ Siemensstraße 2 \\ 9500 Villach, AUSTRIA
}

\begin{abstract}
Continuously increasing complexity of semiconductor manufacturing processes drives the need for wafer to wafer and even within wafer control loops metrology. Applying Virtual Metrology (VM) techniques is one promising approach to reduce the time between process, measurement and corrective actions. Prior to implementation - besides technical aspects like testing - the investment into VM has to be assessed and justified on the basis of reliable and reasonable data. This paper presents the investment assessment for implementing VM algorithms into plasma etcher tools of a model semiconductor fabrication line. Core of the investment calculation is a spreadsheet-based calculation which allows for a results per quarter evaluation. A Discrete Event Simulation (DES) model was developed to produce relevant input data for the spreadsheet calculation. Potential risks - e.g., delivery of wrong VM results - due to the implementation of VM have been identified and evaluated using the standardized method of Failure Mode and Effects Analysis (FMEA).
\end{abstract}

\section{INTRODUCTION AND MOTIVATION}

Currently, Integrated Device Manufacturers (IDM) face a continuous increase in the complexity of processes as well as the requirements of shorter life cycles and faster ramps. Challenges like these are driven by Moore's Law (Moore 1965) and more recently by the More Than Moore movement. IDMs have to improve equipment and process control to maintain their competitiveness and to keep up with competitors from emerging market countries. 
Virtual Metrology (VM) techniques promise to reduce the necessity for real measurement actions and simultaneously support of further advanced process control technologies which increase production efficiency. Schellenberger, Moyne and Rametta (2010) defined VM as a concept to predict post process physical and electrical quality parameters of wafers and/or devices from information collected from the manufacturing tools, e.g., equipment or process parameters, including support from other available sources, e.g., production context information or up-stream metrology. Currently VM algorithms are being developed as described in Baumann and Dimitrov 2011, Chang and Cheng 2005, Chang et al. 2006, Denkena, Schürmeyer, and Eikötter 2010, and Hung et al. 2007. They are not state-of-the-art in IDMs' factories. VM algorithms have to be tested extensively. The investment into VM techniques has to be evaluated in detail. Risks due to the implementation of VM have to be identified and quantified. We approached the investment assessment from several perspectives to achieve a reusable and flexibly adaptable calculation model:

- Spreadsheet-based calculations provide the core of the investment assessment by calculating key economic figures, e.g., the payback period and the Return on Investment (RoI).

- Discrete Event Simulations (DES) enhance and improve the spreadsheet-based calculations by providing profound input data like cycle time and equipment utilization.

- Risk analysis using the standardized method of Failure Mode and Effects Analysis (FMEA) which provides a detailed identification and quantification of risks due to the implementation of VM into the existing IT infrastructure of IDMs. Results will be used as inputs for guidelines which will be set up to foster and align the successful implementation of VM.

\section{BASICS AND METHODS}

\subsection{Scenario}

We decided to develop investment assessment models with the help of a "model fab" since current IDMs" factories are quite different in terms of wafer diameters $(200 \mathrm{~mm} / 300 \mathrm{~mm})$, wafer starts per month, manufacturing technologies and financial production figures. In the past SEMATECH (semiconductor manufacturing technology) developed a $130 \mathrm{~nm}$ logic process which summarized the generic structure of the processes of the individual member companies of the ISMI (International SEMATECH Manufacturing Initiative) cluster as can be found in ISMI (2000) and ISMI/Selete (2000). ISMI (2002) published also the financial key figures of a typical fab using such a generic logic process and key performance indicators for the equipment to be used in such a fab (ISMI 2000). These data are publicly available and their figures are used within this work as a common basis for assessing the investment into novel VM algorithms.

The investment into VM will be assessed by using an example of implementing VM into the plasma etcher tools of the "model fab". Previous calculations and discussions with IDMs promise to yield the highest effect (Koitzsch and Honold 2010).

\subsection{Spreadsheet-Based Calculations}

The basis for any monetary evaluation of an investment is a comparison of the costs for the investment with the financial benefits the company has from the investment. Therefore it is essential for the investment assessment to understand the costs and benefits associated with the anticipated investment into Virtual Metrology.

Costs and benefits of VM are identified and quantified on the basis of economic effects that can be associated with the implementation of VM (see Figure 1): Virtual Metrology is expected to reduce the costs which are caused by the usage of the corresponding expensive metrology equipment. It can help to determine the optimum number of metrology steps within the control strategy of the IDMs. Additionally VM could increase the utilization of process equipment if the characterization result of the process step is available without any time delay. This approach could decrease the cycle time by a reduction of the sample rate at the metrology equipment. Moreover VM is expected to predict process results which 
enable a better yield learning and reduced manufacturing rework. This in turn aids decision making and encourages further work in diagnostic and control methodologies like Fault Detection and Classification (FDC) and Run-to-Run Control (R2R).

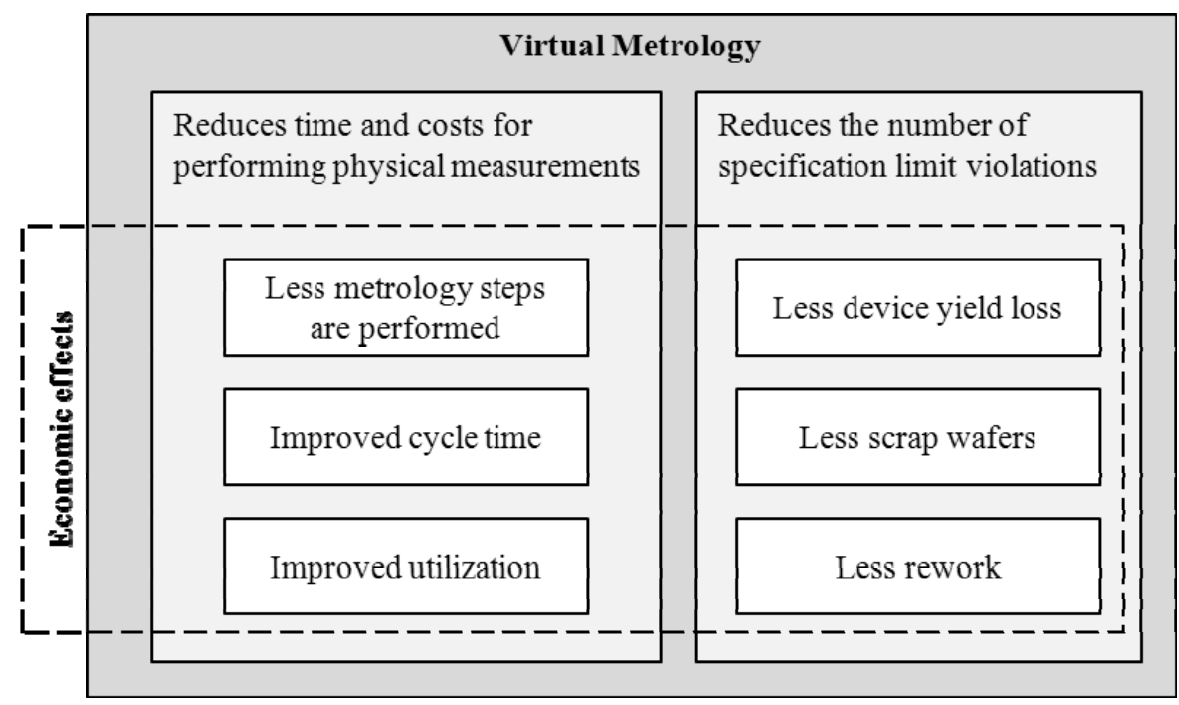

Figure 1: Economic effects of Virtual Metrology

The cost savings because of these identified effects are calculated according to the following ideas:

- Each metrology step which is not performed on a wafer saves the costs of ownership for this metrology step.

- The number of wafers with lower device yield is smaller because the time delay to notice that the occurred process will lead to specification violations of the device parameters at final wafer test is lower. The costs for the process steps between the occurred process and the final wafer test can be saved.

- Early warnings of equipment deviations from specified performance could reduce the number of wafers which must be scrapped or reworked. These indicators are based on the input parameters from the VM.

- The equipment throughput could be increased due to less waiting time for process results from post metrology steps. This approach saves time which could be used to produce more wafers. Additional investments could be avoided for bottleneck equipments depending on their planned utilization margins.

- Each metrology step which is not performed reduces the cycle time. Cycle time improvements increase the degree of efficiency and reduce thereby the capital costs of a fab.

Discrete Event Simulations (DES) were used to enhance and improve the spreadsheet-based investment assessment calculation approach. Thereby the scope of the DES is to provide profound input data, e.g., the cycle time or costs of ownership for every unit process production step within a product chain.

\subsection{Benefits and Challenges of a Discrete Event Simulation (DES) Based Investment Assessment}

DES software is widely used in many industry sectors to simulate the material flow in manufacturing facilities. It is commonly used during planning and optimizing phases in the fab lifecycle. Production systems can be comprehensively analyzed regarding the following aspects by using a DES approach:

- Consequences of a single machine break down

- Cycle time changes

- Equipment utilization capacities 
- Equipment and fab availability

- Output rate depending on the availability of a single equipment

- Optimal number of work piece carrier

- Effects resulting from an increase or decrease of product starts

- Different buffer concepts

The typical approach when carrying out simulation studies is shown in Figure 2. Starting with a planned or already existing manufacturing facility (upper left) a simulation study starts with the development of a formal model. In parallel it is necessary to collect information such as process information for each process and control strategies as well as further information which is relevant to implement the simulation model. After these steps the simulation experiments can be conducted. The result of these simulation experiments is an impression of the expected behavior of the manufacturing facility. Via several simulation runs different fab layout scenarios can be evaluated. On the basis of different alternatives a specific scenario can be selected and used to optimize the planned facility.

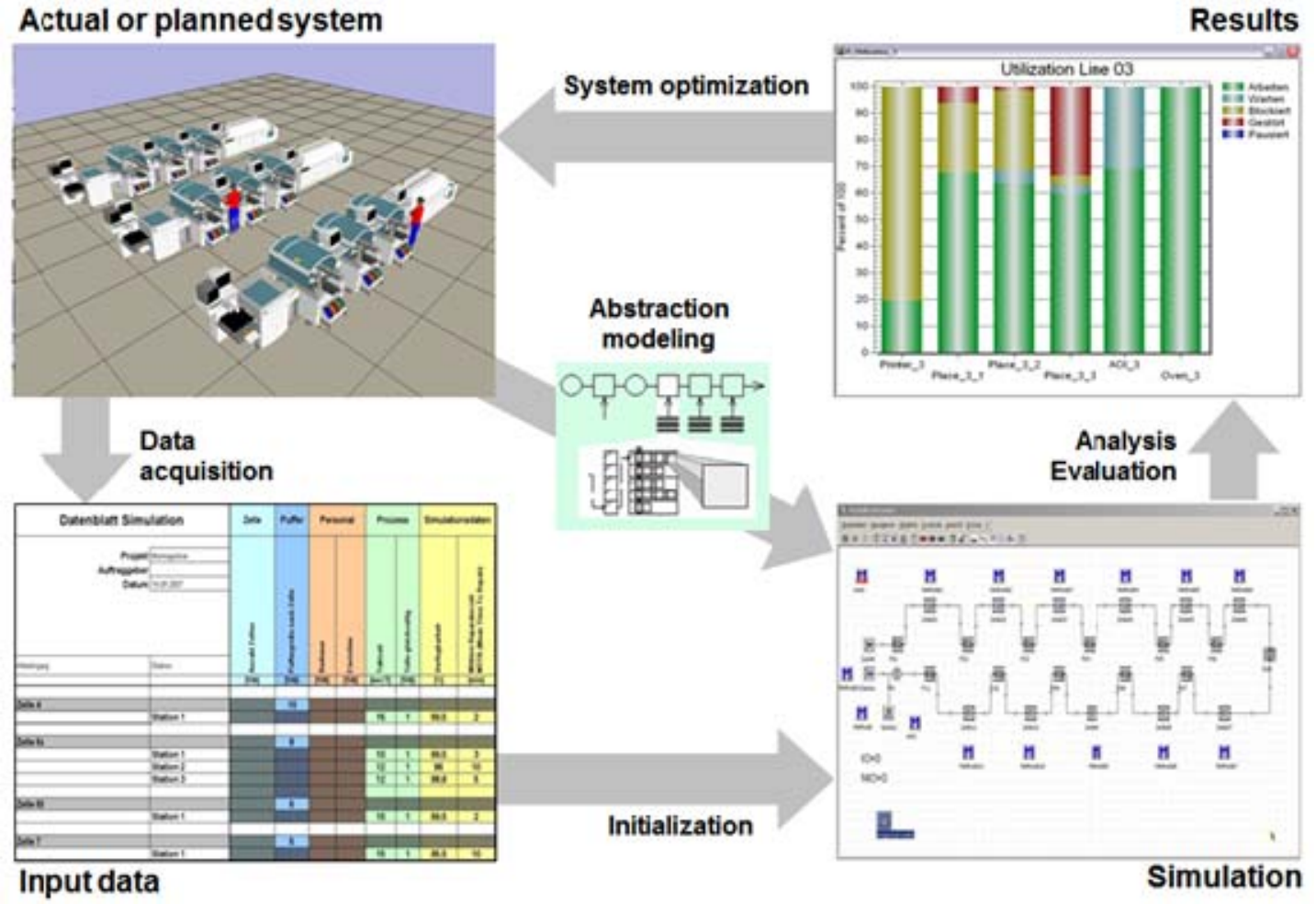

Figure 2: Typical approach for carrying out Discrete Event Simulation studies

Within the scope of this work DES will be used to improve the data quality of several input parameters for investment assessment and therefore also to enhance the quality of the results provided by spreadsheet-based calculations. DES is able to achieve this goal by delivering input figures (e.g., output rates, cycle times, improvement of utilization) for investment assessment that are determined by simulation results in contrast to the educated guesses of these values that are used in the spreadsheet-only approach. Semiconductor process flows are complex and consist of long process chains with many loops. Very often these loops are repeated several times. This setup creates a lot of dynamic effects within the material flow that cannot be assessed reliably by mere calculations making it an ideal sample case for simulation based analyses.

On the downside, the acquisition of simulation determined input figures for some core input parameters to investment assessment does not come for free. In order to get these figures a DES-software 
is needed resulting in either more costs - if the simulation software is purchased and personnel is trained - or more effort - if an own tool is developed or open source solutions are adapted for an IDM. Moreover further input data like a process flow chart is required in order to set up a suitable simulation model. This is crucial since, e.g., the effects of bottlenecks and successive elimination of bottlenecks due to the application of VM and its effects on the output rate cannot be analyzed in simulation studies without a process flow on a step by step level. But the most important factor is that - in the case of semiconductor industry - rather complex simulation models have to be set up and configured which is a time-consuming and therefore an expensive task regarding personnel resources and costs. The spreadsheet-based calculations on the other side only require the equipment specifications and the number of times it is used instead of a detailed process flow. Above all, the setup and configuration steps are less time-consuming and no additional software is needed.

In order to facilitate an easy DES usage for investment assessment in the field of integrated device manufacturing, a system approach is presented in this paper that tackles the mentioned issues. The user will be unburdened during setup and configuration phases of simulation studies making DES usage in the frame of investment assessment much less time-consuming and cost intensive.

\subsection{Risk Assessment}

Besides cost reductions and benefits, the implementation of novel VM algorithms into the existing IT infrastructure of IDMs involves several risks too. These risks have to be identified and quantified. Standardized FMEA (Failure Mode and Effects Analysis) methods have been used in order to perform these tasks.

The FMEA is an analytical method for the systematic identification of a potential weakness. The main idea is predictive failure prevention instead of sub sequential failure repair in order to keep costs low (Kmenta and Ishii 2002). Therefore the so called Risk Priority Number $(R P N)$ is used to prioritize potential failures according to the convention: the occurrence $O$ represents the probability (How likely is the cause and failure mode to occur?), the severity $S$ the gravity (How serious is the impact of the end effect?), and the detection $D$ is the difficulty for identification (How difficult is the cause and failure mode to detect?). This convention of the values $O, S$ and $D$ each ranging in a scale from 1 to 10 leads to the $R P N$ :

$$
R P N=O \cdot S \cdot D
$$

IDM project partners contributed to the evaluation of risks and potential failures regarding the implementation of Virtual Metrology. According to the standardized FMEA spreadsheet shown in Table 1, the $O, S$ and $D$ values and the resulting $R P N$ s have been identified for different potential failures. Table 1 depicts the quantification of two exemplary failures. Example \#1 with an $R P N$ of 240 is of relative high relevance and Example $\# 2$ with an $R P N$ of 36 is of lower relevance.

Table 1: Exemplary FMEA spreadsheet result with one example of higher (\#1) and one example of lower (\#2) relevance

\begin{tabular}{|c|c|c|c|c|c|c|c|c|c|}
\hline 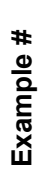 & $\begin{array}{l}\text { Characteris- } \\
\text { tic } \\
\text { Require- } \\
\text { ments }\end{array}$ & $\begin{array}{c}\text { Potential } \\
\text { Failure Mode }\end{array}$ & $\begin{array}{l}\text { Potential } \\
\text { Effect(s) of } \\
\text { Failure }\end{array}$ & 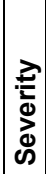 & $\begin{array}{l}\text { Potential } \\
\text { Cause(s)/ } \\
\text { Mechanism(s) } \\
\text { of Failure }\end{array}$ & 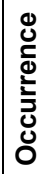 & 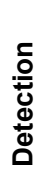 & $\frac{z}{\alpha}$ & Recommended Actions \\
\hline 1 & Accuracy & $\begin{array}{l}\text { Production tool } \\
\text { set down / } \\
\text { maintenance } \\
\text { triggered too late }\end{array}$ & $\begin{array}{l}\text { Scrap produc- } \\
\text { tion (OOC rate } \\
>\text { ) due to run-to- } \\
\text { fail }\end{array}$ & 5 & $\begin{array}{l}\text { Data not com- } \\
\text { plete systemat- } \\
\text { ically }\end{array}$ & 6 & 8 & 240 & $\begin{array}{l}\text { Ensure linearity, sensitivity and } \\
\text { accuracy of models as well as } \\
\text { integrity check of input data }\end{array}$ \\
\hline 2 & Reliability & $\begin{array}{l}\text { Increased real } \\
\text { measurement } \\
\text { frequency }\end{array}$ & $\begin{array}{l}\text { Increased pro- } \\
\text { duction costs }\end{array}$ & 4 & VM-tool down & 3 & 3 & 36 & $\begin{array}{l}\text { Define appropriate KPI for re- } \\
\text { quired uptime (\%) or maximum } \\
\text { downtime (hours/year) of VM- } \\
\text { tool }\end{array}$ \\
\hline
\end{tabular}


FMEA is used as a tool supporting the development and the implementation of VM algorithms. Furthermore, the introduction of Bayesian networks to set up a control tool is proposed. Bayesian networks represent a mathematical approach for probability relations of complex scenarios based on structured graphs. Each state is represented by a node while the directed transitions between states are indicated by arrows. Based on such a graph structure, the Bayesian net also contains state probabilities. Thus, different probability scenarios can be analyzed based on individual and even complex graph structures.

The modeling of FMEA based on Bayesian networks (Fenton and Neil 2007) was done exemplarily using a BNT-Toolbox (Murphy 2001) within the MATLAB ${ }^{\odot}$ software. The example contains a 3 x 3 Bayesian net structure, which is defined via an adjacent matrix. In the next step the state probabilities of the Bayesian net are defined representing normalized $R P N$, following the formalism of the BNT-toolbox. Furthermore, evidences can be stated and thus the marginal - probabilities for a cause to appear - are computed. Finally, the Bayesian net structure is displayed as shown schematically in Figure 3.

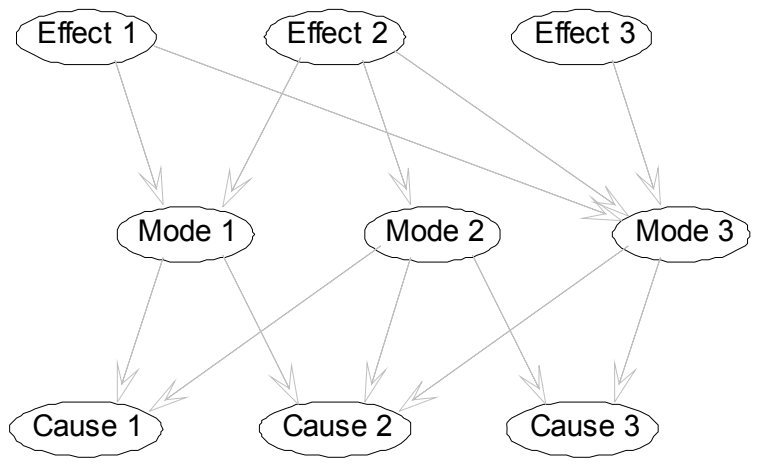

Figure 3: Concept of using Bayesian nets to refine FMEA results

\section{RESULTS}

\subsection{Spreadsheet-Based Investment Assessment}

Potential savings due to the implementation of Virtual Metrology in different equipment types of the model fab were calculated. Results are shown in Figure 4. The first calculation of the economic benefits of VM shows that the highest contribution is due to a higher yield of the processed wafers. The intuitive expectation that savings in metrology steps are important was not supported by the calculation results. Depending on the type of equipment in which VM is implemented, savings due to higher equipment utilization and savings in metrology steps can also play a certain role.

The costs for an investment into Virtual Metrology were estimated together with IDMs. Some parameters such as equipment data were used from the ISMI (2002) fab model. It was assumed that the major implementation work for VM will be executed in a one year project. The costs were calculated for the implementation of Virtual Metrology into two work centers. The hardware and software to run the Virtual Metrology algorithms must be purchased and the algorithm must be adapted to each equipment (modeling). It is also assumed that the process equipment has to be upgraded with additional sensors to deliver appropriate data. The new software must be integrated into the existing Factory Information and Control System. In addition, the involved people of a certain work center must be trained in order to be able to use the new software. The investment into Virtual Metrology software, IT hardware and sensors is depreciated and capital costs were also taken into account for the invested money.

It is assumed that the major costs for the implementation of VM in the first year are due to personnel costs for project management, training and modeling. The capital costs and depreciation for the hardware and software investment are less than $25 \%$ of the overall costs in the first year. In the second year - when the implementation work is completed - mainly running costs of the new software as well as the depreciation and capital costs of the investment will occur. 


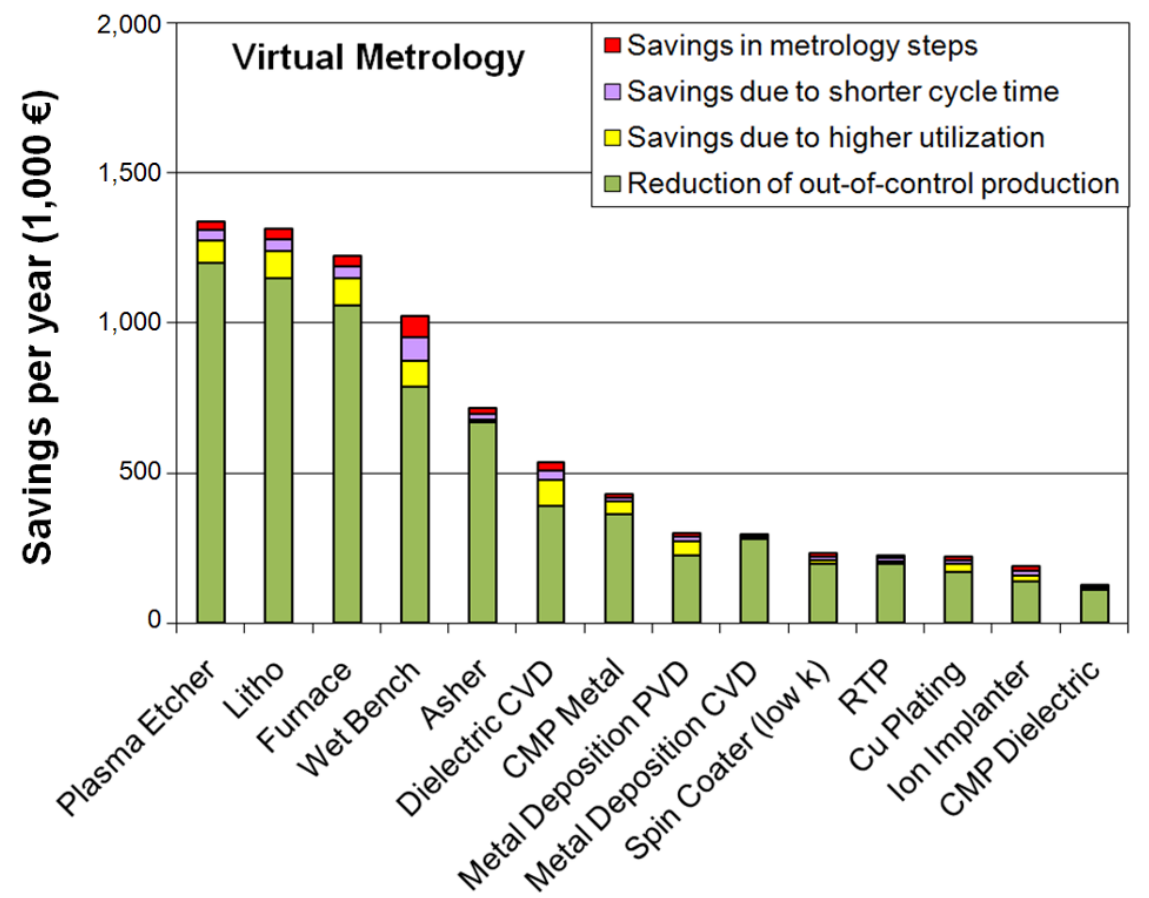

Figure 4: Economic benefits of Virtual Metrology broken down to individual process equipment types of the model fab

Based on the identified and quantified benefits and costs due to $\mathrm{VM}$ a first investment calculation was done. The breakeven was calculated for the implementation of VM algorithms in two work centers of plasma etchers of the model fab. It was assumed that it takes about 6 months until the software is completely installed and the necessary sensors are installed at all plasma etchers. It is then also assumed that the full benefits will not be immediately accomplished but it will take 12 months to ramp-up the installation until the full benefits are achieved.

According to this calculation of costs and benefits, the breakeven for the investment is reached after about 1.5 years, see Figure 5. The economic benefits from the investment into VM balance all the associated costs after this time. After 1.5 years the investment leads to a positive return for the company.

\subsection{System Concept for a Discrete Event Simulation Based Investment Assessment}

In this sub-section a system concept is presented that allows a comfortable combination of DES and investment assessment methods. It is split up into three core components the Process Designer, a third party DES software and the previously described investment calculation spreadsheet, see Figure 6. In our example we used the Plant Simulation software from Siemens PLM as described in Bangsow (2010). Other DES software tools could also be linked with the Process Designer by providing the necessary interfaces. The Process Designer is developed with the multi-platform C++ QT toolkit which provides a Graphical User Interface. The Process Designer is able to gather investment assessment relevant input data and transfer simulation relevant data to the simulation software. The DES especially can provide information about work center utilization and capacity, wafer start time, buffer sizes, output rates per year, mean throughput time of wafer boxes as well as the total conveyor length for a process. Furthermore in the presented system concept the DES software is not directly operated by the user and therefore the user does not need simulation skills. The user only has to provide the necessary input data via Microsoft Excel sheets, that are automatically merged to create the necessary input information for simulation initialization. Besides this the user can configure the simulation scenario within the Process Designer. 
Koitzsch, Merhof, Michl, Noll, Nemecek, Honold, Kleineidam, and Lebrecht

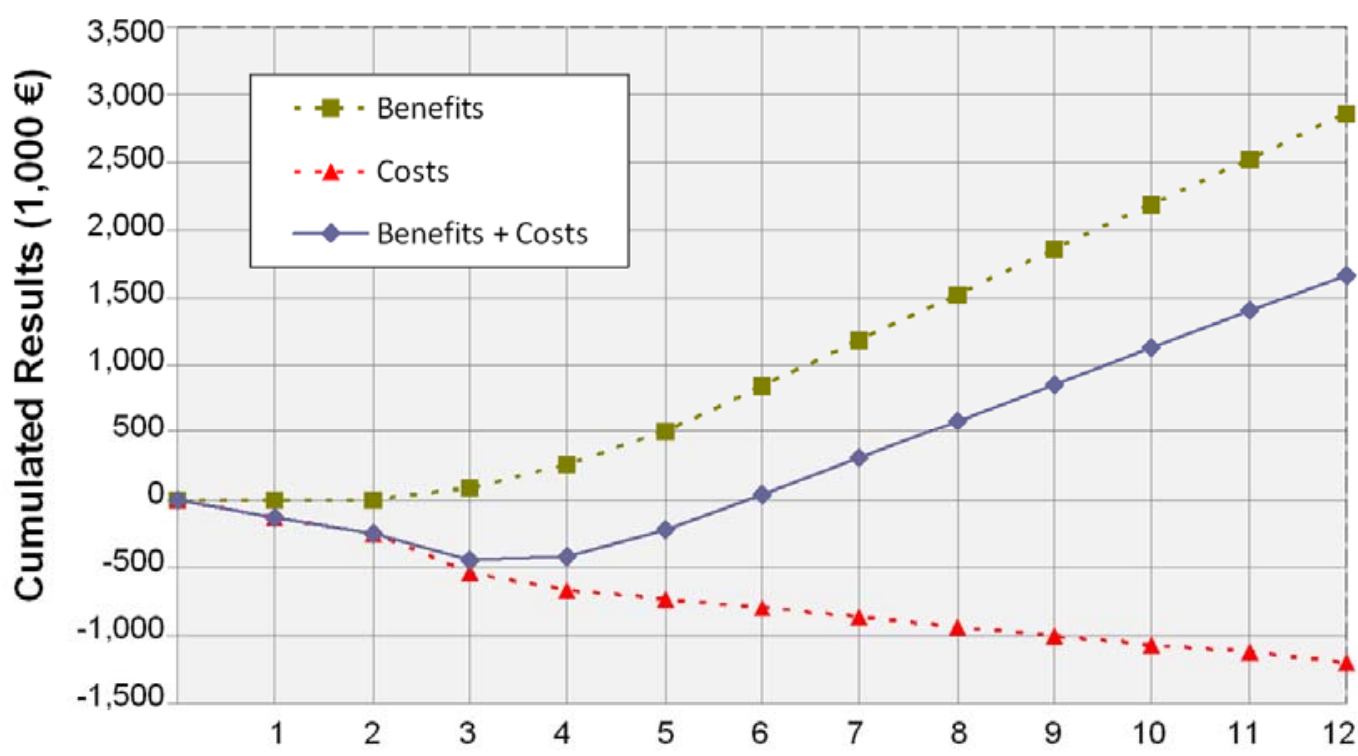

No. of quarter

Figure 5: Break even calculation for the implementation of Virtual Metrology into plasma etcher tools of a model fab

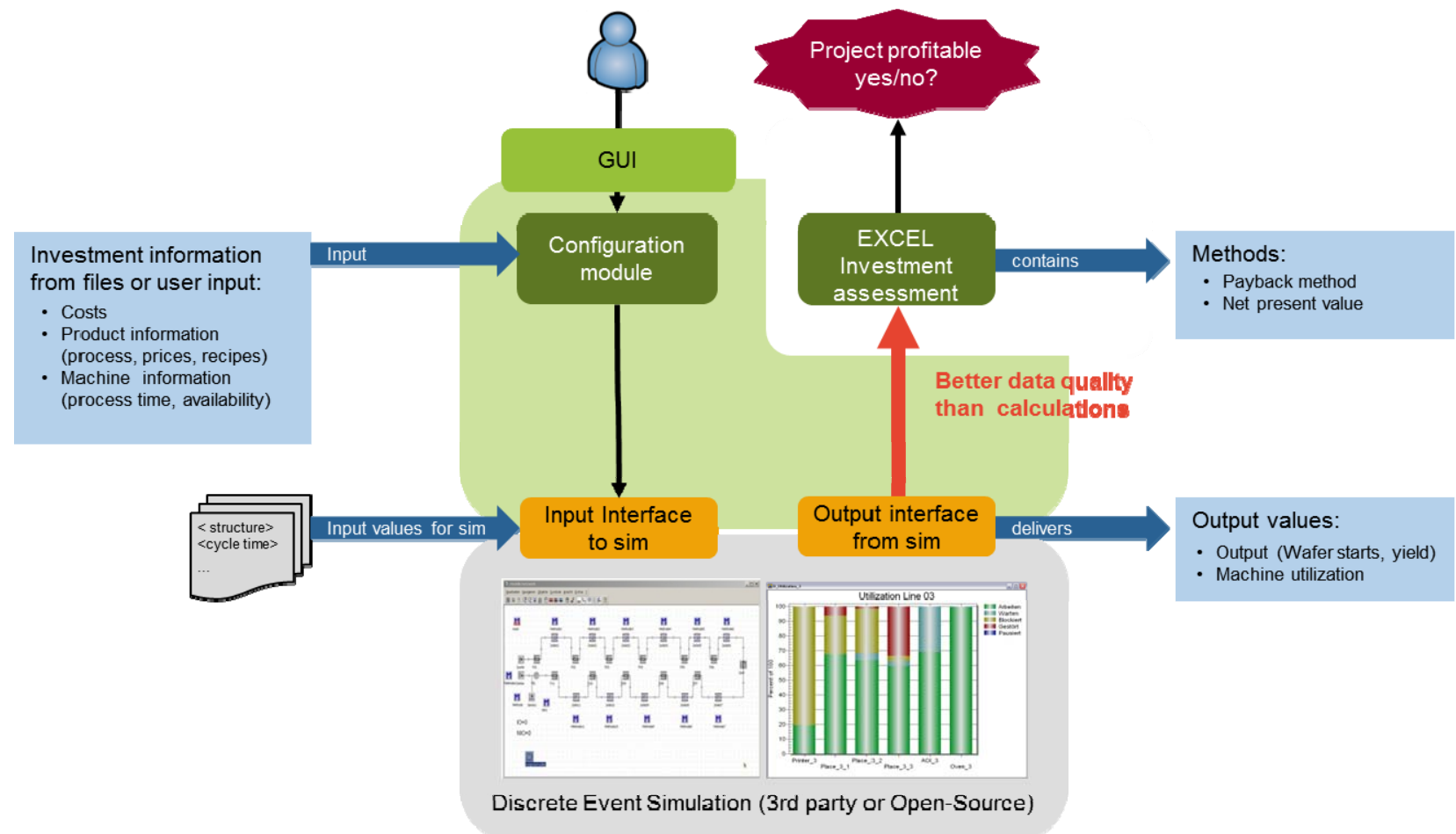

Figure 6: Schematic overview of the system concept

The input data can be separated into the types of machine data, process data and simulation control data. Machine data is needed to specify a single machine for example by name, position and buffer capacity. Process data specifies the name of the process, the throughput time of the process and the process capacity. The simulation control data is needed to specify the basic condition of the simulation such 
as the length of the simulation interval as well as the wafer start interval. In combination with a process flow and optional material tracking information it is possible to generate a material flow model. The data above is used to generate a fab model which includes the machines and their specific processes.

After providing the necessary input data, the Process Designer provides two possibilities for building up a simulation model of the fab. It is possible to model by hand which can be useful if an existing fab model has to be changed or only a subset of the process flow shall be considered in a certain scenario. The main approach is to generate the fab model automatically which is especially useful for setting up large models consisting of several hundred machines or process steps. This can be achieved by using the import function of the Process Designer. This function can handle an Excel-based fab specific work plan which contains a process flow along with process data, machine positions, cost information for each process step as well as information about the conveyor system. Based on those data a corresponding fab model can automatically be created.

After the fab specific simulation model is set up, the Process Designer also supports the user during the performing of simulation studies. As already mentioned the Process Designer is able to communicate with the simulator via interfaces that have to be implemented once per different simulation software that shall be used. This functionality is used to transfer the simulator independent model within the Process Designer to the simulator in order to automatically generate a simulation model within the simulation software. After the model generation different simulation experiments can be parameterized and carried out by using functionalities the Process Designer provides.

After performing simulation runs the results are transferred to the Process Designer via further interfaces. It processes the results and converts them into a defined datasheet of the investment calculation spreadsheet. From there the simulation results can be used for investment assessment replacing the originally used educated guesses. Examples for such values are wafer start time, annual output or utilization of individual machines.

The system concept provides several advantages. A lot of IDMs already use Excel for investment assessment tasks. The proposed system concept can also be used in combination with other investment assessment spreadsheets than the one presented in this work. They only have to integrate the simulation results datasheet or import a .csv-file containing the results. Furthermore due to the modular system architecture the simulator can be spatially distributed which frees the users from having the simulation software installed on their workstations. This functionality is of high value for typical IDMs that operate different production sites throughout the world.

\subsection{Risk Assessment}

According to the mentioned risk assessment methods of FMEA and Bayesian networks, a classification and evaluation of failure causes and effects is required in order to optimize the Virtual Metrology implementation within the fabrication line.

Potential failure effects within the implementation and operation of the VM-tool are for example scrap production lots, decrease of uptime and increase of production costs. These effects might come from one or more of the failure modes as bad coincidence between VM-model and physical measurement values, unreliable VM values, counteractions triggered too late/early or wrong counteraction requested. Hereby the failure causes can be assigned to wrong sensor data, wrong parameterization, model does not represent full process behavior, IT or equipment communication problems. Figure 7 shows an exemplary detail of this context.

\section{DISCUSSION AND NEXT STEPS}

\subsection{Spreadsheet-Based Investment Calculations}

The obtained results of our investment calculations are based on a mixture of data from the model fab and estimations from IDM partners. Thus the results do not represent the situation of a current real factory. 
The presented calculations focus only on the implementation of VM into the plasma etcher tools of the model fab. These calculations will be revised and optimized. In the future the calculation models will be expanded to other equipment types. For the investment calculations more economic measures will be considered, such as the Return on Investment (RoI) and the Net Present Value (NPV).

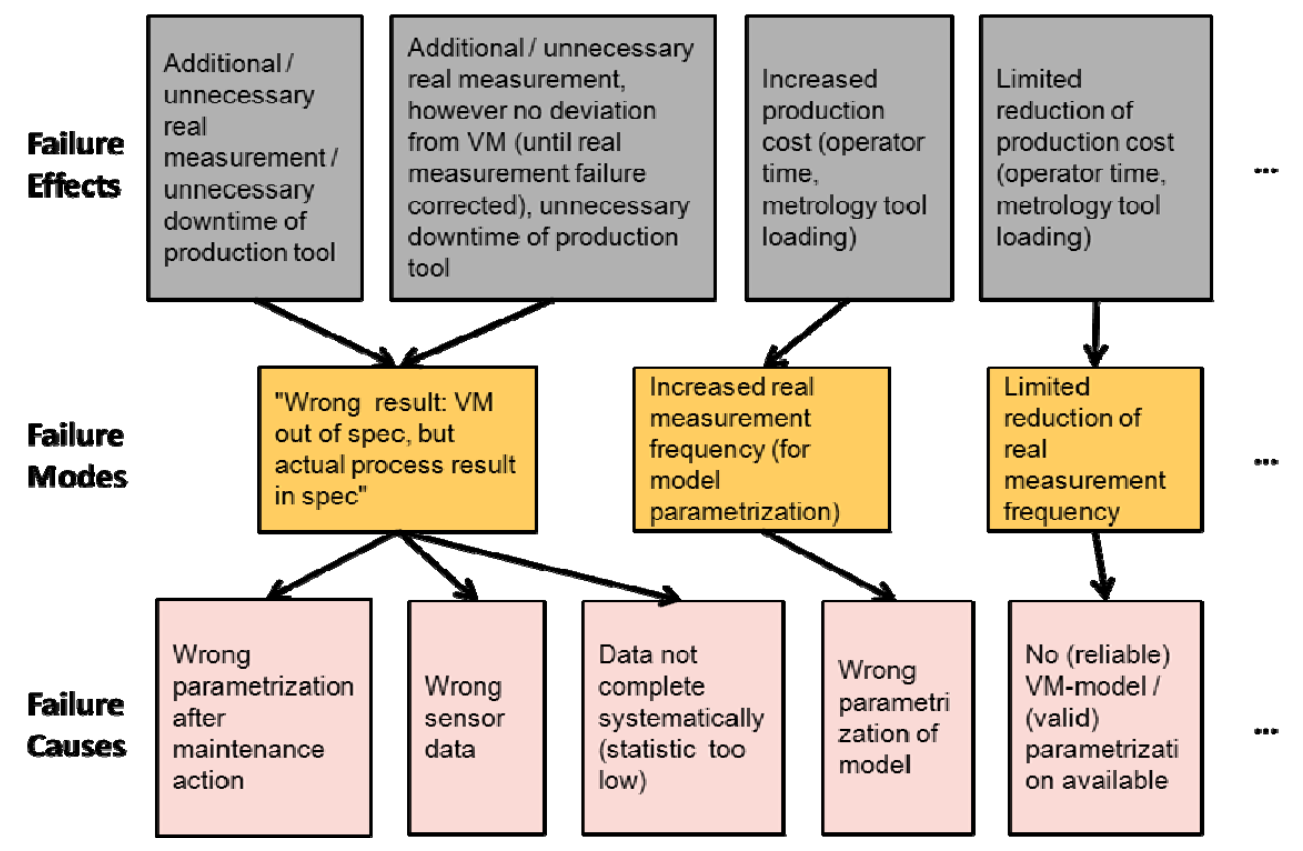

Figure 7: Exemplary detail of potential failure causes, modes and effects sorted according to Bayesian network structure

\subsection{Discrete Event Simulation Based Investment Assessment}

The proposed system concept provides a way to integrate the benefits - namely a better data basis in order to get more reliable conclusions - of DES simulation into investment assessment while at the same time eliminating existing downsides. First, the time and cost intensive step of setting up and configuring a simulation model is eliminated by providing functions that are able to carry out this task automatically. Furthermore an easy to use GUI was developed that allows the use to parameterize and perform simulation studies without having to know how to operate the underlying simulation software. In addition interfaces are provided to allow the integration of existing spreadsheet-based investment assessment tools with DES based results.

In future work, the developed system concept will be used to evaluate the effects of VM application in the previously described SEMATECH process scenario (see section 2.1). In order to do this two simulation models - one with and one without VM - will be set up in order to evaluate the impact of the deployment of VM. The VM simulation model differs from the non-VM fab model by a shorter process chain since measurement steps can be omitted. Furthermore failure rates of machines that are influenced by VM will be adapted in order to model the lower out of control (OOC)-rate.

\subsection{Risk Assessment}

Accompanying the implementation of Virtual Metrology within an IDM's manufacturing line, risk assessment is proposed to be done with the suggested methods FMEA and Bayesian nets in order to individually evaluate potential risks. A refinement of the risk assessment models for the implementation of Virtual Metrology based on experiences in a pilot production is required. As a next step FMEA results already presented in a Bayesian network frame, will be refined with actual values from the FMEA to devel- 
op a control tool for the implementation of novel VM algorithms. Results of the risk assessment will serve as a valuable contribution to guidelines for the implementation of novel VM algorithms into existing IDMs' IT-infrastructure.

\section{SUMMARY AND CONCLUSION}

In this paper we presented an investment assessment for the implementation of novel VM algorithms into two work centers of plasma etcher tools of a model fab. The investment is assessed from three different sides. Spreadsheet-based calculations as the core of the investment assessment will be enhanced and improved by Discrete Event Simulations providing profound information about input parameters like the cycle time. Identifying and quantifying the risks due the implementation of VM tops off the comprehensive assessment of the investment into VM. Future work will take into account other equipment types, check of the sensitivity of input parameters as well as the elaboration of guidelines for the implementation of VM algorithms.

\section{ACKNOWLEDGMENTS}

The authors would like to thank all project partners who provided input data, fruitful discussion and ideas to the presented work which was funded by the EU-project IMPROVE, contract no. 120005.

\section{REFERENCES}

Bangsow, S. 2010. "Manufacturing Simulation with Plant Simulation and SimTalk." Berlin Heidelberg: Springer-Verlag.

Baumann, M., T. Dimitrov. 2011. "Simulation zur Auswahl und Parametrierung einer Produktionssteuerung”. In Productivity Management vol. 1, pp 23-25. Gito mbH Verlag, Berlin.

Chang, Y.-C.J., and F.-T. Cheng. 2005. "Application Development of Virtual Metrology in Semiconductor Industry." In $31^{\text {st }}$ Annual Conference of IEEE Industrial Electronics Society, IECON 2005, 124129.

Chang, Y.-J; Y. Kang, C.-L. Hsu, C.-T. Chang, and T.Y. Chan. 2006. "Virtual Metrology Technique for Semiconductor Manufacturing." In Proceedings of International Joint Conference on Neural Networks, 5289-5293. Vancouver, BC, Canada.

Denkena, B., J. Schürmeyer, and M. Eikötter. 2010. "Berücksichtigung temporärer Effekte von Lebenszykluskosten in der Technologiebewertung." In $Z W F$ 105, 11:959-963. Munich: Carl Hanser Verlag.

Fenton, N. E., and M. Neil. 2007 "Managing Risk in the Modern World: Bayesian Networks and the Applications." London Mathematical Society, Knowledge Transfer Report.

Hung, M. H., T. H. Lin, P. H. Chen, and R. C. Lin. 2007. "A Novel Virtual Metrology Scheme for Predicting CVD Thickness in Semiconductor Manufacturing." IEEE/ASME Transactions on Mechatronics 12(3):308-316.

ISMI. 2000. "130 nm Cu logic process." International SEMATECH Manufacturing Initiative.

ISMI. 2002. Fab Model, Wafer Cost Comparison Calculator. Version 1.0. International SEMATECH Manufacturing Initiative.

ISMI/Selete. 2000. "Unified Equipment Performance Metrics for $130 \mathrm{~nm}$ Technology." Version 2.0, $300 \mathrm{~mm}$ equipment. International SEMATECH Manufacturing Initiative.

Kmenta, S., and K. Ishii. 2000. "Scenario-based FMEA: A Life Cycle Cost Perspective." In Proceedings of the ASME Design Engineering Technical Conference. Baltimore, MD.

Koitzsch, M., and A. Honold. 2010. "Evaluation of Economic Effects as the Basis for Assessing the Investment into Virtual Metrology." In Proceedings of the AEC-/APC-Symposium, 172-194. Austin, USA.

Moore, G.E. 1965. “Cramming More Components Onto Integrated Circuits.” Electronics 38(8):114-117. 
Murphy, K. 2001. "The Bayes Net Toolbox for Matlab.” Computing Science and Statistics 33:17861789.

Schellenberger, M., J. Moyne, F. Rametta. 2010. "General Introduction of APC; Tutorial Introducing the Concepts of APC." In Proceedings of the $10^{\text {th }}$ European Advanced Equipment Control/Advanced Process Control (AEC/APC) Conference. Italy.

\section{AUTHOR BIOGRAPHIES}

MATTHIAS KOITZSCH has been a research scientist with Fraunhofer IISB since 2006. He is active in the areas of technology development for the microelectronics industry and return on investment calculations. He holds a diploma in electrical engineering from the Friedrich-Alexander University of ErlangenNuremberg. E-mail: matthias.koitzsch@iisb.fraunhofer.de.

JOCHEN MERHOF holds a diploma in computer science from the University of Erlangen Nuremberg. Since 2008, he is a staff member at the Institute for Manufacturing Automation and Production Systems of the University Erlangen Nuremberg. His research interests are planning and simulation, with the main focus on smart automation and simulation in factory operations. E-mail: jochen.merhof@faps.unierlangen.de.

MARKUS MICHL has been a research scientist with the Institute for Manufacturing Automation and Production Systems of the University Erlangen Nuremberg since 2006. His research interests are the diagnosis of production systems and the optimization of maintenance. He holds a diploma in computer science from the University of Erlangen Nuremberg. E-mail: markus.michl@faps.uni-erlangen.de.

HUMBERT NOLL is Head of the Department "Micro- and Nanosystems" at the University of Applied Sciences Wiener Neustadt, Austria. He holds a PhD in Physics from the University of Graz, Austria. For more than 20 years he was director of Research and Development at the semiconductor company austriamicrosystems AG. Furthermore, he is involved in numerous national and international organizations in the field of micro- and nano-electronics and systems. E-mail: humbert.noll@fhwn.ac.at.

ALEXANDER NEMECEK received his PhD degree in electrical engineering from Vienna Technical University, Austria. He also received the Joseph-Ressel award from Vienna Technical University, Austria in 2007 where he worked as scientific staff member at the Institute of Electrical Measurement and Circuit Design. Currently, he is a senior scientist at the department of Micro- and Nanosystems of the University of Applied Sciences Wiener Neustadt, Austria. E-mail: alexander.nemecek@fhwn.ac.at.

ALFRED HONOLD is president of InReCon AG. He has worked nearly 20 years in various positions in the semiconductor industry. Dr. Honold holds a diploma and a doctorate in physics from the University of Stuttgart as well as a diploma in economics from the FernUniversität Hagen. He can be reached via e-mail at: alfred.honold@inrecon.de.

GERHARD KLEINEIDAM works with InReCon AG. He can be reached via e-mail at: gerhard.kleineidam@inrecon.de.

HOLGER LEBRECHT is development engineer and within this function team lead for Run-to-Run Control (R2R) solutions at Infineon Technologies Austria AG. He is responsible for the development and rollout of R2R systems at Infineon's Frontend sites. He holds a diploma in electrical engineering from the University of Applied Sciences Kärnten and an IPMA level B certification as a Senior Project Manager. E-mail: holger.lebrecht@infineon.com. 